\title{
Immunological assays for chemokine detection in in-vitro culture of CNS cells
}

\author{
Supriya D. Mahajan ${ }^{1}$, Stanley A. Schwartz ${ }^{1}$ and Madhavan P.N. Nair ${ }^{1 *}$
}

${ }^{1}$ Department of Medicine, Division of Allergy, Immunology, and Rheumatology and State University of New York and Buffalo General Hospital, Kaleida Health 100 High Street, Buffalo, NY 14203.

\begin{abstract}
*To whom correspondence should be addressed: Dr. Madhavan PN Nair Ph.D., Research Professor, Department of Medicine, Division of Allergy, Immunology and Rheumatology, 301 Multi Research Bldg., Buffalo General Hospital, 100 High Street, Buffalo, NY 14203. Tel: 716859 2985; Fax: 716859 2999; Email: mnair@acsu.buffalo.edu
\end{abstract}

Submitted: February 24, 2003; Revised: February 25, 2003; Accepted: March 12, 2003; Published: April 7, 2003

Indexing terms: Chemokines, Central Nervous System, Reverse Transcriptase Polymerase Chain Reaction.

\begin{abstract}
Herein we review the various methods currently in use for determining the expression of chemokines by CNS cells in vitro. Chemokine detection assays are used in conjuction with one another to provide a comprehensive, biologically relevant assessment of the chemokines which is necessary for correct data interpretation of a specific observed biological effect. The methods described include bioassays for soluble chemokine receptors, RNA extraction, RT-PCR, Real - time quantitative PCR, gene array analysis, northern blot analysis, Ribonuclease Protection assay, Flow cytometry, ELISPOT, western blot analysis, and ELISA. No single method of analysis meets the criteria for a comprehensive, biologically relevant assessment of the chemokines, therefore more than one assay might be necessary for correct data interpretation, a choice that is based on development of a scientific rationale for the method with emphasis on the reliability and relevance of the method.
\end{abstract}

\section{INTRODUCTION}

Chemokines, also known as chemotaxic cytokines, are secreted proteins that function as chemoattractants, mediating the recruitment of various subsets of leukocytes to sites of tissue damage to mediate specific immunological functions $(1,2)$. Chemokines were first discovered in 1987. They play a role in activating the immune system's response to infection. These signaling molecules attach themselves to specific binding sites (receptors) on immune cells, trigger the cells to respond to infection, and call more immune cells to infected areas to fight invading microbes. The chemokine molecules share structural similarities, including four conserved cysteine residues which form disulphide bonds in the tertiary structure of the proteins. Traditionally, the chemokine superfamily has been divided into two subgroups: $\mathrm{C}-\mathrm{X}-\mathrm{C}$ (where $\mathrm{X}$ is any amino acid) and $\mathrm{C}-\mathrm{C}$, according to whether an intervening residue occurs between the two cysteines. This structural distinction has been shown to delineate a general, though not absolute, distinction in the biological properties of these molecules. Most C-X-C chemokines are chemoattractants for neutrophils (and to some extent lymphocytes) but not monocytes, whereas C-C chemokines appear to attract monocytes, basophils, eosinophils, and lymphocytes (including NK cells) but not neutrophils. A third "C" branch of these molecules are called lymphotactin. The representative of these $\mathrm{C}$ chemokines is a chemoattractant for lymphocytes and NK cells, but it does not attract either monocytes or neutrophils.

Chemokines mediate their activities by binding to target cell surface chemokine receptors that belong to the large family of $\mathrm{G}$ protein-coupled, seven transmembrane (7 TM) domain receptors (also called serpentine receptors) (3). Based on the receptor nomenclature established at the 1996 Gordon Research Conference on chemotactic cytokines, the chemokine receptors that bind $\mathrm{CXC}$ chemokines are designated CXCRs and the receptors that bind $\mathrm{CC}$ chemokines are designated CCRs. Leukocytes have generally been found to express more than one receptor type. The various CXCRs and CCRs are known to exhibit overlapping ligand specificities. It was only in 1995, however, that the connection between chemokines and HIV infection became clear. Cytotoxic T lymphocytes (CTLs) secrete certain chemokines that can suppress HIV activity. Three specific chemokines-RANTES, MIP1 $\alpha$, and MIP1 $\beta$ were found to work together to block HIV replication. Suppressive factors, secreted by CTLs may also be involved in HIV suppression. AIDS researchers have shown that a specific receptor molecule called CD4, on the surface of immune cells which allows HIV to enter cells however the CD4 alone was not sufficient for HIV to infect the immune cells. A second receptor needed for the entry of HIV into cells was identified and named "fusin" (CXCR4) because it enables certain strains

(C) 2003. Biological Procedures Online. Published in Biological Procedures Online under license from the author(s). Copying, printing, redistribution and storage permitted. 
of HIV to fuse with and enter immune cells called T cells. An analysis of the structure of fusin revealed that it was a receptor for chemokines, the family of signaling molecules that includes beta-chemokines, which were shown to suppress HIV activity (4). Yet another chemokine receptor, called CCR5, was necessary for the entry of HIV into immune cells called macrophages. This receptor was already known to be the binding site for the chemokines recently found to play a pivotal role in suppressing HIV infection. The new findings suggest that the three chemokines suppress HIV replication by binding to the same receptors needed by certain strains of HIV to enter immune cells. It might be possible to treat HIV infection by developing drugs that block the coreceptors needed for HIV entry. Vaccines that trigger the activity of immune cells that inhibit the binding of HIV to coreceptors may be able to prevent infection. Although still in its early stages, the development of therapies and vaccines based on chemokine receptors promises to strengthen a growing arsenal of weapons for use in fighting HIV.

Expression of a variety of chemokines and receptors was shown to be increased in HIV encephalitis brain tissues particularly in areas of neuroglial reaction (4). Presence of chemokine receptors on neurons may be involved in the pathogenesis of neurologic damage in AIDS patients. Macrophages are potential carriers of latent HIV-1 and on activation may be implicated in spreading the infection to other neighbouring cells, such as microglia or astrocyte. Microglia, resident macrophages of the $\mathrm{CNS}$, may contribute to this process by elaborating chemoattractants that are capable of recruiting leukocytes across the blood-brain barrier. HIV infection of macrophages and subsequently astrocytic cells can contribute to the establishment of a chronic inflammatory state in the CNS, eventually resulting in HIV encephalitis, by increasing the secretion of pro-inflammatory cytokines. A great deal of attention has recently been focused on the regulation of chemokine expression and function following exposure to opioids, cannabinoids, or cocaine $(5,6,7)$. It is not surprising that these drugs would be found to alter chemokine expression, since there is a rather extensive literature base showing that drugs of abuse can modulate the production of other cytokines. Certain drugs of abuse can alter the expression and/or function of the chemokine receptors (7). For example, pre-treatment with opioids leads to an inhibition of chemotaxis of neutrophils, monocytes, and dendritic cells to either complement-derived chemotactic factors or the chemokines MIP-1 $\beta$, RANTES, MCP-1 and IL-8.

The levels of the chemokines in body fluids / tissues or culture supernatants can be measured by a broad variety of assays (8) as shown in the Table 1.
Table 1:

Measurement of chemokines in culture supernatants and serum

- ELISA / Colorimetric methods / bioassays for soluble receptor levels $(9,22,23)$

Chemokine production by different populations of immune cells

- Flow cytometric Analysis (19)

Differential Gene Expression technologies for transcripts for chemokines /chemokine receptors, Chemokine gene profiling

- mRNA based assays - including RT-PCR / Real time Quantitative-PCR / Nothern Blot analysis / Rnase Protection assays (RPA), Gene array analysis (11, 12, 15, $16,17,18,21)$

Single cell assays for chemokine secretion

- $\quad$ ELISPOT (24)

We investigated the in-vitro effects of various drugs of abuse on gene expression and production of the various $\beta$ chemokines, MCP-1, MIP-1 $\beta$ respectively and their specific receptors, CCR2b (MCP-1), CCR3 (MIP-1 $\beta$ ), and CCR5 (MIP-1 $\alpha \& \beta$ ) on the neuronal cell lines, U373 and U87. We have outlined below a brief summary of each of the methods used in our laboratory for chemokine detection, however we have only provided results using a couple of the mentioned techniques to illustrate how the chemokine detection assay are used in conjuction with one another to provide a comprehensive, biologically relevant assessment of the chemokines which is necessary for correct data interpretation of a specific observed biological effect.

\section{MATERIALS AND METHODS}

\section{Cell culture}

Neuronal cell lines U373 (ATCC HTB) and U87(ATCC HTB-14) were obtained from the American Tissue Culture Collection(ATCC). Both cell lines cells are derived from a human malignant glioma / grade III tumor. Cultures are maintained in complete medium [Eagles MEM with nonessential amino acids, sodium pyruvate $1 \mathrm{mM}$ and Earl's BSS $90 \%$ and 10\% Fetal bovine serum]. U373 and U87 cells (3.2 X 10 $10^{-6} 60 \mathrm{~mm}$ dish) were cultured with drugs of abuse like morphine at concentrations ranging from $10^{-7}$ to $10^{-15} \mathrm{M}$ for 24 to $96 \mathrm{hr}$ at $37^{\circ} \mathrm{C}$ in a $5 \% \mathrm{CO}_{2}$ incubator. Supernates were harvested and stored at $-70^{\circ} \mathrm{C}$ and chemokines quantitated by ELISA, RNA was extracted from the cells for RT-PCR, real time quantitative PCR and northern blot analysis. 


\section{Bioassays for soluble chemokine receptors}

Biological activity of chemokine receptors is determined in cellular assays, where the chemokines receptors are available as soluble proteins. Chemotaxis in leukocytes is mediated through binding of soluble chemokines to transmembrane Gprotein coupled receptors. Chemokines selectively recruit and activate a variety of cells during inflammation. Interactions between cell surface glycosaminoglycans (GAGs) and chemokines drive the formation of immobilized gradients of chemokines at the site of inflammation, directing this recruitment. Chemokines can therefore form complexes with both cell surface and soluble GAGs. Soluble GAG chemokines complexes are unable to bind the receptor, thus, resulting in a block of the biological activity.Soluble chemokine receptors can be found in the blood and extracellular fluid. These soluble receptors result from enzymatic cleavage of the extracellular domain of cell-bound chemokine receptors. The released soluble fragments can bind chemokine molecules, thereby neutralizing their activity (9). Bioassays are divided into four broad categories based on the type of function measured in the target cells incubated in the presence of a chemokine: a) assays which measure proliferation, b) assays of cytotoxicity, c) assays dependent on the induction of a specific cell function such as chemotaxis, and d) assays estimating the quantity of a protein induced in a target cell. Bioassays for chemokine receptors are sensitive in the pictogram range, but are not specific, and neutralizing with a chemokine specific antibody is necessary to confirm the identity of the measured chemokine receptor. This is because several different chemokines in the unknown sample could mediate the same biological activity. Bioassays are more time consuming and laborious than immunoassays. They require target cell line which is modulated by the biological response being measured. Bioassays are mainly used for validation purposes rather than routine chemokine measurements. Bioassays are more often used for confirmation and validation of the results obtained by other chemokine detection methods. Bioassays are infrequently performed, because they are labor intensive, analysis of the dose response curves generated in the bioassays requires extensive curvefitting statistics based computer analysis, and they are not appropriate for large scale screening and rapid throughput.

\section{RNA extraction}

Cytoplasmic RNA was extracted by an acid guanidiniumthiocyanate-phenol-chloroform method as described $(10,11)$.

\section{Gene Array Analysis}

Gene arrays are solid supports upon which a collection (oligonucleotides numbers ranging from 20-1000) of genespecific nucleic acids have been placed at defined locations, by spotting onto a membrane. In array analysis, a nucleic acid containing sample is labeled and then allowed to hybridize with the gene-specific targets on the array. The nucleic acids attached to arrays are called "targets," whereas the labeled nucleic acids comprising the sample are called "probes." Based on the amount of probe hybridized to each target spot, information is gained about the specific nucleic acid composition of the sample. The major advantage of gene arrays is that they can provide information on thousands of targets in a single experiment. Currently the solid supports upon which nucleic acids are arrayed are either glass slides or nylon membranes. Typically, fluorescently labeled probes are used with glass arrays, while radiolabeled probes are used with membranes. Depending on the type of array, the arrayed nucleic acids may be composed of oligonucleotides, PCR products or cDNA vectors or purified inserts. The sequences may represent entire genomes and may include both known and unknown sequences or may be collections of sequences of cytokines. Many pre-made and custom arrays are available from commercial manufacturers although many labs prepare their own arrays with the help of robotic arrayers. The methods of probe labeling, hybridization, and detection depend on the solid support to which the sequences are bound. Gene arrays may be used for sequence identification (e.g. mutation analysis) or differential expression analysis of two or more RNA samples. Gene arrays have become a powerful tool for comparing complex sample RNA populations. Using array analysis, the expression profiles of normal and tumor tissues, treated and untreated cell cultures, developmental stages of an organism or tissue, and different types of tissues can be compared (12). Nylon membrane arrays are typically hybridized with ${ }^{32} \mathrm{P}$-dNTP labeled probes and analyzed by a phosphorimager or autoradiography using appropriate densitometric scanning software. A different array must be used for each sample analyzed. A typical experiment involves isolating RNA from two tissue or cell samples. The RNAs are reverse transcribed using labeled nucleotides and target specific, oligo dT, or random-sequence primers to create two labeled cDNA populations. The two cDNAs are hybridized to two identical arrays. After washing, the hybridized signal on each array is detected and analyzed. The signal emitting from each gene-specific spot is compared between the populations. Genes expressed at different levels in two samples generate different amounts of labeled cDNA and this results in spots on the array with different amounts of signal (13). Differences in expression of specific sequences are often validated by another method of analysis such as RT-PCR, Northern analysis or nuclease protection assays. These same methods can be used for relative or absolute quantitation of specific messages of interest identified by array analysis.

\section{RT-PCR}

Extracted RNA was used for RT-PCR as described by the manufacturer employing a Perkin Elmer kit (Cat \# N8080143). Briefly, RNA was reverse transcribed to make a DNA copy for use in PCR (14). One $\mu \mathrm{g}$ of RNA was added to a tube containing $5 \mathrm{mM} \mathrm{MgCl}_{2}, 1 \mathrm{mM}$ of each dNTP (A, T, G, C), 50 
$\mathrm{mM} \mathrm{KCl,} 10 \mathrm{mM}$ pH 8.3 Tris Buffer, $2.5 \mathrm{uM}$ oligo dT, 20 units of RNAse-inhibitor and 50 units of $\mathrm{MuLV}$ reverse transcriptase. The mixture was incubated at $45^{\circ} \mathrm{C}$ for $35 \mathrm{~min}$, heated to $95^{\circ} \mathrm{C}$ for $5 \mathrm{~min}$ and placed on ice until used for PCR. The newly synthesized cDNA was then amplified by PCR using specific sense and antisense primers for the genes of interest along with a housekeeping gene, glucose-3-phosphate dehydrogenase $(\mathrm{G} 3 \mathrm{PDH})$ or $\beta$-actin, as a control. Briefly, to each tube, a $10 \mu \mathrm{l}$ sample of the RT product in a final concentration of $2 \mathrm{mM} \mathrm{MgCl}_{2}, 10 \mathrm{mM}$ Tris $\mathrm{pH} 8.3,50 \mathrm{mM}$ $\mathrm{KCl}$, plus $0.02 \mu \mathrm{M}$ of both the 5' and 3' primers of the genes of interest, and 2.5 units of Taq polymerase were added. The mixture was placed in a thermocycler for 30 cycles of $95^{\circ} \mathrm{C}$ for $30 \mathrm{sec}, 60^{\circ} \mathrm{C}$ for $30 \mathrm{sec}$ and $74^{\circ} \mathrm{C}$ for $1 \mathrm{~min}$. The PCR conditions were modified slightly for each chemokine/chemokine receptor gene to obtain optimal results. Samples were separated by $1-1.2 \%$ agarose gradient gel electrophoresis along with molecular weight markers for reference. Resultant bands were visualized with UV light, photographed, size determined and optical density (OD) was quantified using a scanning densitometer. All values were normalized to the constitutive expression of the housekeeping gene.

\section{Real Time Quantitative RT-PCR}

Relative abundance of each mRNA species was assessed using the SYBR green master mix from Stratagene to perform real time quantitative PCR (15). The ABI Prism 5700 sequence detection system detects and plots this increase in fluorescence versus PCR cycle number to produce a continuous measure of PCR amplification. To provide precise quantification of initial target in each PCR reaction, the amplification plot is examined at a point during the early log phase of product accumulation. This is accomplished by assigning a fluorescence threshold above background and determining the time point at which each sample's amplification plot reaches the threshold (defined as the threshold cycle number or $\mathrm{C}_{\mathrm{T}}$ ). Differences in threshold cycle number are used to quantify the relative amount of PCR target contained within each tube.

\section{Calculation of Relative Expression}

Relative expression of mRNA species was calculated using the comparative $\mathrm{C}_{\mathrm{T}}$ method. All data were controlled for quantity of RNA input by performing measurements on an endogenous reference gene, $\beta$-actin or G3PDH. In addition, results on RNA from treated samples were normalized to results obtained on RNA from the control, untreated sample. Briefly, the analysis was performed as follows:

For each sample, a difference in $\mathrm{C}_{\mathrm{T}}$ values $\left(\Delta \mathrm{C}_{\mathrm{T}}\right)$ was calculated for each mRNA by taking the mean $\mathrm{C}_{\mathrm{T}}$ of duplicate tubes and subtracting the mean $\mathrm{C}_{\mathrm{T}}$ of the duplicate tubes for the reference RNA ( $\beta$-actin or $\mathrm{G} 3 \mathrm{PDH})$ measured on an aliquot from the same $\mathrm{RT}$ reaction.

$\Delta \mathrm{C}_{\mathrm{T}}=\mathrm{C}_{\mathrm{T}}$ (test gene $)-\mathrm{C}_{\mathrm{T}}(\beta$-actin $)$

The $\Delta \mathrm{C}_{\mathrm{T}}$ for the treated sample was then subtracted from the $\Delta \mathrm{C}_{\mathrm{T}}$ for the untreated, control sample to generate a $\Delta \Delta \mathrm{C}_{\mathrm{T}}$.

Thus $\Delta \Delta \mathrm{C}_{\mathrm{T}}=\Delta \mathrm{C}_{\mathrm{T}}($ treated sample $)-\Delta \mathrm{C}_{\mathrm{T}}($ untreated control $)$

The mean of these $\Delta \Delta \mathrm{C}_{\mathrm{T}}$ measurements was then used to calculate expression of the test gene $\left(2^{-\Delta \Delta \mathrm{CT}}\right)$ relative to the reference gene and normalized to the untreated control as follows:

Relative Expression $=2^{-\Delta \Delta \mathrm{CT}}$

This calculation assumes that all PCR reactions are working at $100 \%$ efficiency. All PCR efficiencies were found to be $>95 \%$; therefore, this assumption introduces minimal error into the calculations.

\section{Northern Hybridization}

Northern blot analysis was performed as recommended in Current Protocols in Molecular Biology $(11,16,17)$. Briefly, a total of $10-20 \mu \mathrm{g}$ of denatured RNA was loaded per lane and was resolved using a denaturing gel containing formaldehyde to obtain good resolution of the denatured RNA and then transferred onto a nylon membrane. After crosslinking, the membrane is then prehybridized at $68^{\circ} \mathrm{C}$ for $1 \mathrm{hr}$ followed by hybridization at $68^{\circ} \mathrm{C}$ overnight using Ultrahyb (Ambion, Austin, TX) mixed with the ${ }^{32} \mathrm{P}$ labeled specific probe. The cDNA probe was generated using the TOPO -TA cloning kit from Invitrogen (cat \# K4500-01). The cDNA probe was labelled using the Random primer labeling method, with $\mathrm{P}^{32}$ using a PRIME it- II kit from Stratagene. After hybridization, the membrane was washed with low and high stringency buffers and the blots were exposed to Biomax-MS film (Eastman KODAK, Rochester, NY). The autoradiograph obtained was then scanned and bands quantified using a densitometer. All results were normalized to the housekeeping gene, $\beta$-actin.

\section{Ribonuclease protection assay}

The ribonuclease protection assay (RPA) is a sensitive method used for the detection of low-abundant mRNA in a complex mixture of total cellular RNA (18). The RPA is based on solution hybridization of a ${ }^{32} \mathrm{P}$-labeled riboprobe to target mRNA. Radioactive riboprobes have a short useful life and disintegrate within 7 days of synthesis. To circumvent the problems of using radioactivity, non-radioactive RPA using biotinylated riboprobes can be developed. 


\section{Riboprobe synthesis}

Total RNA was isolated from cells with the Trizol reagent (Sigma, St. Louis, MO). The cDNA was synthesized in a 25 $\mu \mathrm{L}$ volume containing $2 \mu \mathrm{g}$ total RNA, $0.5 \mu \mathrm{g}$ random hexamer, $500 \mu \mathrm{M}$ dNTPs, $10 \mathrm{mM}$ DTT, $20 \mathrm{U}$ RNase inhibitor and $200 \mathrm{U}$ MMLV reverse transcriptase (Promega, Madison, WI) at $37^{\circ} \mathrm{C}$ for $60 \mathrm{~min}$. The PCR reactions were carried out in a $50 \mu \mathrm{L}$ volume containing $5 \mu \mathrm{L}$ of the RT product, $2.5 \mathrm{mM}$ $\mathrm{MgCl}_{2}, 200 \mathrm{mM}$ dNTPs, $400 \mathrm{nM}$ of each sense and antisense primers, and 2.5 U Taq DNA polymerase (Sigma, St. Louis, $\mathrm{MO}$ ). Riboprobes were synthesized by in vitro transcription carried out in a $20 \mu \mathrm{L}$ volume containing $5 \mathrm{~mL}$ of PCR products, $20 \mathrm{U}$ RNase inhibitor, 20 units of T7 RNA polymerase (Ambion, Austin, TX), $0.5 \mathrm{mM}$ each of ATP, GTP, UTP with $0.3 \mathrm{mM}$ CTP and $0.2 \mathrm{mM}$ biotin-labeled-14-CTP (Gibco BRL, Grand Island, NE) at $37^{\circ} \mathrm{C}$ for $2 \mathrm{~h}$.

\section{Ribonuclease protection assay}

Ten $\mu \mathrm{g}$ of total RNA was hybridized with $40 \mathrm{pg}$ of riboprobe overnight at $45^{\circ} \mathrm{C}$. Single-stranded RNA was then digested with a mixture of $250 \mathrm{U} / \mathrm{mL}$ RNase A and $10,000 \mathrm{U} / \mathrm{mL}$ RNase $\mathrm{T} 1$ for $30 \mathrm{~min}$ at $37^{\circ} \mathrm{C}$. After inactivation of RNase with $20 \mu \mathrm{L}$ of $10 \%$ SDS and $0.5 \mu \mathrm{L}$ of $20 \mathrm{mg} / \mathrm{mL}$ proteinase $\mathrm{K}$ for $20 \mathrm{~min}$ at $37^{\circ} \mathrm{C}$, protected RNA was extracted with $400 \mu \mathrm{L}$ of phenol / chloroform / isoamylalcohol (25:24:1) and separated on a $5 \%$ acrylamide/ $8 \mathrm{M}$ urea denaturing gel. The protected RNA was electrophoretically transferred (Transblot, BioRad) onto a positively-charged nylon membrane (Schleicher \& Schuell, Germany) with $0.5 \mathrm{X}$ TBE at $400 \mathrm{~mA}$ for $1 \mathrm{hr}$. After UV-crosslinking, the membrane was exposed to BioMax X-ray film (Eastman KODAK, Rochester, NY) overnight. Autoradiographs were scanned and images were analyzed using densitometric software (Syngene, MD).

\section{FACS analysis}

Multicolor immunofluorescent staining was used to identify and quantify the number of U373 cells expressing the surface chemokine receptor, CCR5, in response to treatment with morphine. Approximately $1 \times 10^{6}$ cells were treated with $10^{-7} \mathrm{M}$ morphine for $24 \mathrm{hr}$ and cells were harvested, trypsinized, washed, and suspended in staining buffer. FACS conditions were optimized by adjusting the settings for photomultiplier tube voltage and compensation using appropriate cell surface staining controls and quadrant markers were set using specified isotype controls for the flurochrome-conjugated antibody used (19). Monoclonal antibodies (mAbs) against CCR5 were conjugated to fluroscein isothiocyanate (FITC) and the matched isotype control was obtained from BD BiosciencesPharmingen (San Diego, CA). For surface marker analysis, Fc receptors were pre-blocked by incubating cells with an excess of irrelevant purified IgG and then stained with $0.5 \mu \mathrm{g}$ of FITC-conjugated $\mathrm{mAb}$ specific for the cell surface antigen,
CCR5. Cells were washed twice with staining buffer, pelleted by centrifugation at $250 \mathrm{xg}$ and the supernatant fluid removed. Cells were then washed in PBS and fixed and then resuspended in staining buffer prior to flow cytometric analysis using a FACS Calibur instrument (BD Biosciences, San Jose, CA). Stained cells were subjected to light scatter analysis and a fixed population of cells were gated after quandrant markers were set, based on the isotype control and represented as FL-1 (FITC-labeled) on the $\mathrm{X}$ axis. Cells positive for CCR5 were expressed as a percentage of the total cells gated (20).

\section{Western blot analysis}

Western or immunoblotting is a commonly employed technique for the detection of protein antigens in complex mixtures (21). Cells were lysed and protein extracted using Mammalian Protein Extraction Reagent (M-PER ${ }^{\mathrm{TM}}$ ) (Pierce Inc., Rockford, IL). Samples were then separated by SDSpolyacrylamide gel electrophoresis. Separated proteins are then transferred to a membrane (usually nitrocellulose, polyvinyl pyrolidon, or nylon). These membranes are incubated with an antibody specific for the protein of interest which binds to the protein band immobilized on the membrane. The antibody is then visualized with a detection system that is usually based on a secondary protein binding to Ig chains which is linked to a color-yielding reaction. We believe that the effects of morphine on chemokine gene regulation observed may be mediated via the $\mu$ opioid receptor, therefore we used western blot analysis with anti- $\mu$ opioid receptor antibody to determine if neuronal cells express the $\mu$ opioid receptor and if its expression can be modulated by morphine. The anti- $\mu$ opioid receptor antibody (BD Biosciences-Pharmingen, Catalog \# 60751A, Lot \# M034672) is an affinity purified, polyclonal antibody produced in rabbits against the human $\mu$ opioid receptor that recognizes both human and rat $\mu$ opioid receptors. The antibody is used for western blot analysis at a concentration of $2 \mu \mathrm{g} / \mathrm{ml}$ and identifies the $\mu$ receptor as a 45 $\mathrm{kD}$ band. U373 and U87 cells and normal human astrocytes were cultured with $10^{-7} \mathrm{M}$ morphine and washed. Total protein was extracted using M-PER ${ }^{\mathrm{TM}}, 30 \mu \mathrm{g}$ of total protein was loaded per lane and separated using a 7.5\% SDS-Tris glycine PAGE gel. Gels were blotted onto nitrocellulose membranes (Novex, San Diego, CA) and blocked overnight by incubating with $1 \mathrm{X}$ TBS containing $0.1 \%$ Tween and $5 \%$ nonfat dry milk. Membranes were probed with the above antibodies against the $\mu$ opioid receptor. After incubation with the primary antibody, the membrane was incubated for $2 \mathrm{hr}$ at room temperature with biotin-conjugated, goat anti-rabbit IgG antibody. After 3 washes of $10 \mathrm{~min}$ each, blots were incubated for another 30 min with a streptavidin-alkaline phosphatase conjugate (GibcoLife Technologies, Grand Island, NY) followed by colorimetric detection using NBT/BCIP reagent (Roche, Indianapolis, IN). 


\section{ELISA}

The ELISA assays employ the quantitative sandwich enzyme immunoassay technique $(22,23)$. A monoclonal antibody specific for a particular chemokine is pre-coated onto a microplate. Standards and samples are pipetted into the wells and the chemokine present in the sample or standard is bound by the immobilized antibody. After washing away any unbound substances, an enzyme-linked polyclonal antibody specific for the chemokine of interest is added to the wells. Following a wash to remove any unbound antibody-enzyme reagent, a substrate solution is added to the wells and color development in proportion to the amount of chemokine bound to the plate is measured as optical density based on the color intensity using a spectrophotometer at a specific wave length. We quantitated chemokine protein secretion in culture supernates using commercially available, highly specific and sensitive ELISA kits from R\&D systems (Minneapolis, MN) and Biosource International (Camarillo, CA) according to the instructions supplied by the manufacturer.

\section{ELISPOT assay to quantify the secretion of cytokines by $T$ lymphocytes}

The enzyme-linked immunospot (ELISPOT) assay is a powerful tool for detecting and analyzing individual cells that secrete a particular protein in vitro (24). Although originally developed for analyzing specific antibody-secreting cells, the assay has been adapted for measuring the frequency of cells that produce and secrete a variety of other molecules such as cytokines. The protocol involves activation of the $\mathrm{T}$ lymphocytes ( $\mathrm{T}$ cells) in vitro with antigen. The wells of the ELISPOT plate are coated with antibody specific for the assayed cytokine. The antibody binds to the nitrocellulose base of the ELISPOT plate. Activated T cells are then transferred to the ELISPOT plate, and the cytokines are released during the overnight incubation period. Those cytokines that are released locally around each T cell bind to and are therefore "captured" by the specific antibody. The cells and any excess cytokines are washed off. A second antibody that is also specific for the cytokine of interest is added; this antibody is coupled to an enzyme that is capable of converting a substrate into an insoluble colored product. The plates are washed once more, and the enzyme substrate is added. The substrate is converted into the insoluble product, forming spots of color representing areas of captured cytokines that are secreted by adjacent $T$ cells. The colored spots are counted using a stereomicroscope or digital-imaging system.

The ELISPOT assay has the following advantages: the cytokine released can be detected at the level of single cells, allowing for direct determination of cytokine-producing cell frequencies. This assay is more sensitive than ELISA and intracellular staining. The sensitivity of the assay enables measurement of very low frequencies of cytokine-producing cells (e.g. $\sim 1 / 300,000$ ). Objective and rapid analyses of cytokine producing cell numbers (spots), and relative amounts of cytokine produced per cell (spot size) are now possible. Recent developments in assay plate design and in high-throughput ELISPOT plate-reader instrumentation have significantly improved the utility of the ELISPOT method.

\section{RESULTS AND DISCUSSION}

Since their development in the early 1990s, differential gene expression technologies have been applied to a multitude of biological challenges, both for the purpose of basic biological research and as a valuable tool for the discovery, validation and development of pharmaceuticals (25).

We believe that chemokine detection using the techniques listed above will provide useful clinical information about HIV infection by examining the association between different chemokine profiles and disease progression (26). We have presented results of for our neuronal cell lines which have been treated with morphine at $10^{-7}$ and $10^{-9} \mathrm{M}$ concentration. Herein we have shown how various techniques including, RT-PCR, ELISA, real-time quantitative PCR, western blot and flow cytometry can be used to investigate the effects of treatment of CNS cells with morphine. Results from all these chemokine detection methods demonstrates that morphine downregulates the expression of chemokines while simultaneously upregulating the expression of their receptors. Discussed below are the various methodologies used for chemokine analysis, outlining the special features of each.

To identify the specific genes that are modulated by a specific biological process we used gene array analysis. Gene expression profiling provides an overview of the activation of many genes involved in various disease processes. However, the conventional microarray (gene chip), with the ability to examine tens of thousands of genes are now being replaced by a second generation of arrays that are more focused, application-specific and lower-cost. The gene arrays we use used for our study are made to our specifications by Superarray Inc. (Bethesda MD). They consist of a membrane with cDNA from about 20 different genes allowing more focused analyses of specific biological activities.

To maintain a high level of reliability, sensitivity and specificity, these arrays have cDNA fragments from 300bp to $600 \mathrm{bp}$, selected by computer algorithms to minimize crosshybridization. Sometimes sequences outside the coding region are included to make the specificity unique for each gene. All cDNA fragments spotted on the array are indexed by Genbank accession numbers to allow the end-user to validate the array data with independent methods, such as northern blots or quantitative RT-PCR.

We developed a semi-quantitative RT-PCR assay to analyze expression of the mRNA of the human chemokines, RANTES, 
MIP-1 $\beta$, MCP-1, and IL-8 as well as their respective receptors, CCR3, CCR5, CCR2b, and CXCR2. The assay showed a high sensitivity and within assay and inter-assay variability was below 5\%. This method allows the direct, semi-quantitative comparison of the expression of different chemokine mRNA levels from relatively small cell numbers or small tissue specimens. Although RT-PCR is a sensitive tool for assaying mRNA, it is not precise due to the exponential nature of the amplification process. Also it is an end point analysis and thus provides only semi-quantitative results. Indeed, small variations in the amplification efficiency can result in dramatic changes in product yields. To overcome this difficulty, realtime, quantitative PCR was developed. Real-time experiments are performed on a sequence detection instrument capable of detecting fluorescence from samples during each cycle of a PCR protocol. In real-time analysis the accumulation of the product is measured and reported during every cycle of the reaction. These measurements allow a threshold cycle $(\mathrm{Ct})$ to be determined for each reaction. The $\mathrm{Ct}$ occurs when the sequence detection application begins to detect an increase in signal associated with an exponential increase in PCR product. The passive reference dye, ROX, does not participate in the amplification reaction but provides an internal reference to which the reporter-dye signal can be normalized during data analysis. Because the product is measured immediately upon amplification above the background, the problem of limiting reagent during PCR can be monitored. Normalization is necessary to correct for fluorescent fluctuations due to changes in concentration or volume. Normalization controls ensure that the quantitative PCR reaction is yielding similar amplification efficiency in each run. Housekeeping genes like G3PDH or $\beta$ actin are used because they are abundant in most samples and show little variation between experiments.

Quantitative real-time PCR is routinely performed in our laboratory since the cost and availability of the Taqman probes and SYBR green Q-PCR master mixes have decreased significantly due to competition. Quantitative PCR shows a high sensitivity (below 60 cDNA molecules / $10 \mu \mathrm{l}$ reaction) and dynamic range ( 8 log units); both within assay and interassay variability were below 0.06 log units and accuracy was $\pm 0.06 \log$ units for all chemokines tested in our laboratory using the 5700 Gene Amp Sequence detection system. Quantitative results based on $\mathrm{Ct}$ are more accurate than results derived from end point determinations because $\mathrm{Ct}$ derived quantification is determined from measurements taken during the early exponential phase of PCR amplification before efficiency is affected by limiting reagents and product reannealing.

Gene expression data provide an understanding of gene regulation in a specific biological process at the transcriptional level. However protein detection methods such as ELISA and western blots are necessary to determine whether the transcribed gene is ultimately translated into protein. ELISA is the easiest and fastest assay to precisely measure pg quantities of proteins. ELISA kits to facilitate the assay of chemokines in biological samples are commercially available. Using such kits, we have measured levels of various chemokines in serum from patients as well as supernates of cultured cells. Results obtained using kits from several manufacturers differed slightly but were well within acceptable ranges of variance. This variability may be due to differences in specificity and sensitivity of the unique monoclonal antibodies employed in each kit. Factors influencing variability between ELISA kits may include: (i) denaturation of the recognized epitope within the cytokine, (ii) fragmentation of the cytokine following enzymatic cleavage (iii) binding of cytokines to undefined ligands, (iv) variable glycosylation of the cytokines, and (v) recognition of precursor forms of cytokines which would interfere with their measurements.

With the many different cytokine assays available, one must decide on which will provide the best information for the study being undertaken. Both the choice of chemokine assay and evaluation of the results are complex issues. No single method can answer all likely questions. Thus more than one assay may be necessary for optimal results. Examples derived from our own studies demonstrating the use of multiple assays for detecting gene expression by cells is provided below. The data presented in Figures 1, 2, 4 and 5, and Tables 2 and 3 show the effect of morphine treatment on chemokine and chemokine receptor gene expression by CNS cells. Figure 3 shows the effect of morphine on $\mu$ receptor expression by CNS cells as determined by western blot. All the data presented in Figures 1 to 5 is representative of three separate experiments. The statistical method used for data analysis was analysis of variance between groups (ANOVA).

\section{REFERENCES}

1. Power CA, Proudfoot AE. The chemokine system: novel broad-spectrum therapeutic targets. Curr Opin Pharmacol 2001; 1(4):417-424.

2. Fernandez EJ, Lolis E. Structural studies of chemokines that inhibit HIV-1 entry. Antivir Chem Chemother 2001; 12(1):43-49.

3. Horuk R. Chemokine receptors. Cytokine Growth Factor Rev 2001; 12(4):313-335.

4. Minagar A, Shapshak P, Fujimura R, Ownby R, Heyes M, Eisdorfer $\mathrm{C}$. The role of macrophage/microglia and astrocytes in the pathogenesis of three neurologic disorders: HIV-associated dementia, Alzheimer disease, and multiple sclerosis. J Neurol Sci 2002; 15:13-23.

5. Perez-Castrillon JP, Perez-Arellano J, Garcia-Palomo J, Jimenez-Lopez A, De Castro S. Opioids depress in vitro human monocyte chemotaxis. Immunopharmacology 1992; 23(1):57-61.

6. Liu Y, Blackbourn DJ, Chuang LF, Killam KF, Chuang RY. Effects of in vivo and in vitro administration of morphine sulfate upon rhesus macaque polymorphonuclear cell phagocytosis and chemotaxis.. J Pharmacol Exp Ther 1992; 263(2):533-539. 
7. Grimm MC, Ben-Baruch A, Taub DD, Howard OMZ, Resau JH, Wang JM, Ali H, Richardson R, Snyderman R, Oppenheim JJ. Opiates transdeactivate chemokine receptors: delta and $\mathrm{mu}$ opiate receptor-mediated heterologous desensitization. J Exp Med 1998; 188(2):317325.

8. Whiteside TL. Cytokine Assays. Biotechniques 2002; 33:S4 -S15.

9. Wong ML, Sternberg EM. Immunological assays for understanding neuroimmune interactions. Arch Neurol 2000; 57(7):9489-9452.

10. Chomczynski P, Saachi N. Single step method of RNA isolation by acid guanidinium thiocyanate-phenolchloroform extraction. Anal Biochem 1987; 162:156-159.

11. Darbre P. Basic molecular biology: essential techniques. John Wiley \& Sons, New York, NY: 1-29, 1999.

12. DeRisi J, Penland L, Brown PO, Meltzer PS, Ray M, Chen $\mathrm{Y}, \mathrm{Su} \mathrm{YA}$, Trent JM. Use of a cDNA Microarray to Analyse Gene Expression Patterns in Human Cancer. Nature Genetics 1996; 14:457-460.

13. Schena M, Shalon D, Davis RW, Brown PO. Quantitative Monitoring of Gene Expression Patterns with a Complimentary DNA Microarray. Science 1995; 270:467470.

14. Mullis KB, Faloona FA, Scharf S, Saiki RK, Horn G, Erlich HA. Specific enzymatic amplification of DNA in vitro: The polymerase chain reaction. Cold Spring Harbor Symposia on Quantitative Biology 1986; 1-124.

15. Ong YL, Irvine A. Quantitative real-time PCR: a critique of method and practical considerations. Hematology 2002; 7(1):59-67.

16. Thomas PS. Hybridization of denatured RNA and small DNA fragments transferred to nitrocellulose. Proc Natl Acad Sci USA 1980; 77(9):5201-5205.
17. Nobrega FG, Dieckmann CL, Tzagoloff A. A rapid method for detecting specific RNA transcripts by hybridization to DNA probes in solution. Anal Biochem 1983; 131(1):141145.

18. Prediger EA. Detection and quantitation of mRNAs using ribonuclease protection assays. Methods Mol Biol 2001; 160:495-505.

19. Darzynkiewicz Z, Crissman HA eds. Flow Cytometry, Vol. 33 Methods in Cell Biology. San Diego, CA; Academic Press, Inc., 1-475, 1990.

20. Robinson J, Paul MNG eds. Current Protocols in Cytometry. John Wiley \& Sons, Inc. New York, NY: 1-59, 1998.

21. Dunn MJ. Detection of total proteins on western blots of 2D polyacrylamide gels. Methods Mol Biol 1999; 112:319329.

22. Perlmann H, Perlmann P. Enzyme-Linked Immunosorbent Assay. In: Cell Biology: A Laboratory Handbook, Academic Press, Inc., San Diego, CA: 322-328, 1994.

23. Crowther JR. Methods in Molecular Biology, Vol. 42ELISA: Theory and Practice. Humana Press, Totowa, NJ: $1-102,1995$.

24. Stott DI. Immunoblotting, dot-blotting, and ELISPOT assays: methods and applications. J Immunoassay 2000; 21(2-3):273-296.

25. Findlay JWA, Smith WC, Lee JW, Nordblom GD, Das I, DeSilva BS, Khan MN, Bowsher RR. Validation of immunoassays for bioanalysis: a pharmaceutical industry perspective. J Pharm Biomed Anal 2000; 21(6):1249-1273.

26. Bienvenu J, Monneret G, Fabien N, Revillard JP. The clinical usefulness of the measurement of cytokines. Clin Chem Lab Med 2000; 38(4):267-285. 
FIGURES AND TABLES
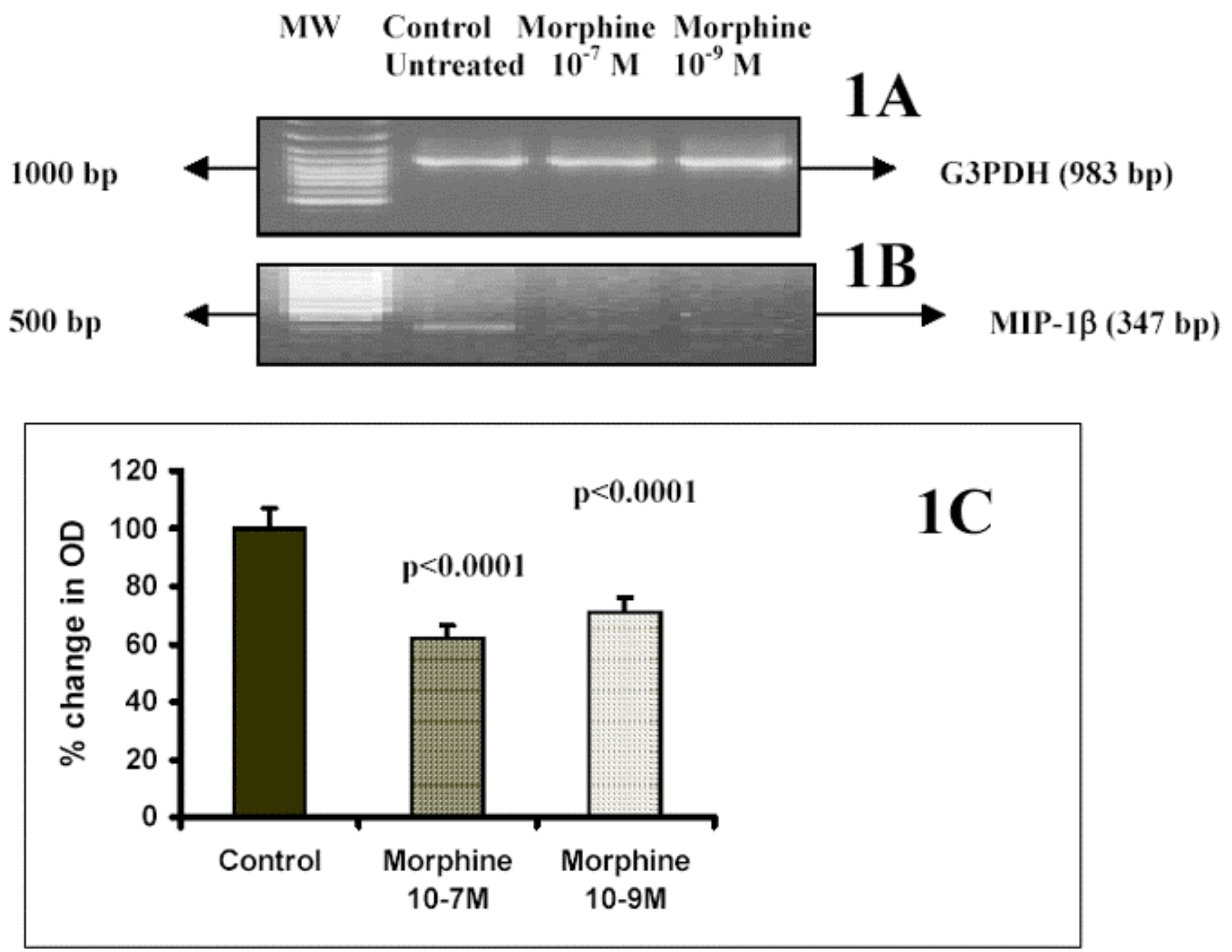

Fig. 1: Results of semiquantitative RT-PCR show that morphine inhibits MIP-1ß gene expression in U373 cells. U373 cells $\left(3 \mathrm{X} 10^{6} / \mathrm{ml}\right)$ were cultured with or without morphine for $24 \mathrm{hr}$. RNA was extracted, reverse transcribed and amplified by PCR using housekeeping gene, G3PDH, and MIP-1 $\beta$ specific primers. PCR products were separated by electrophoresis on a 1.2\% agarose gel. 1A: G3PDH expression remained unchanged at both morphine concentrations. 1B: Morphine inhibits MIP-1 $\beta$ gene expression at $10^{-7}$ and $10^{-9} \mathrm{M}$ concentrations. 1C: Quantitation of the effect of morphine on MIP-1 $\beta$ gene expression by densitometry after nomalization with corresponding values of G3PDH expression in A; these data are the mean \pm SD of 3 separate experiments. 


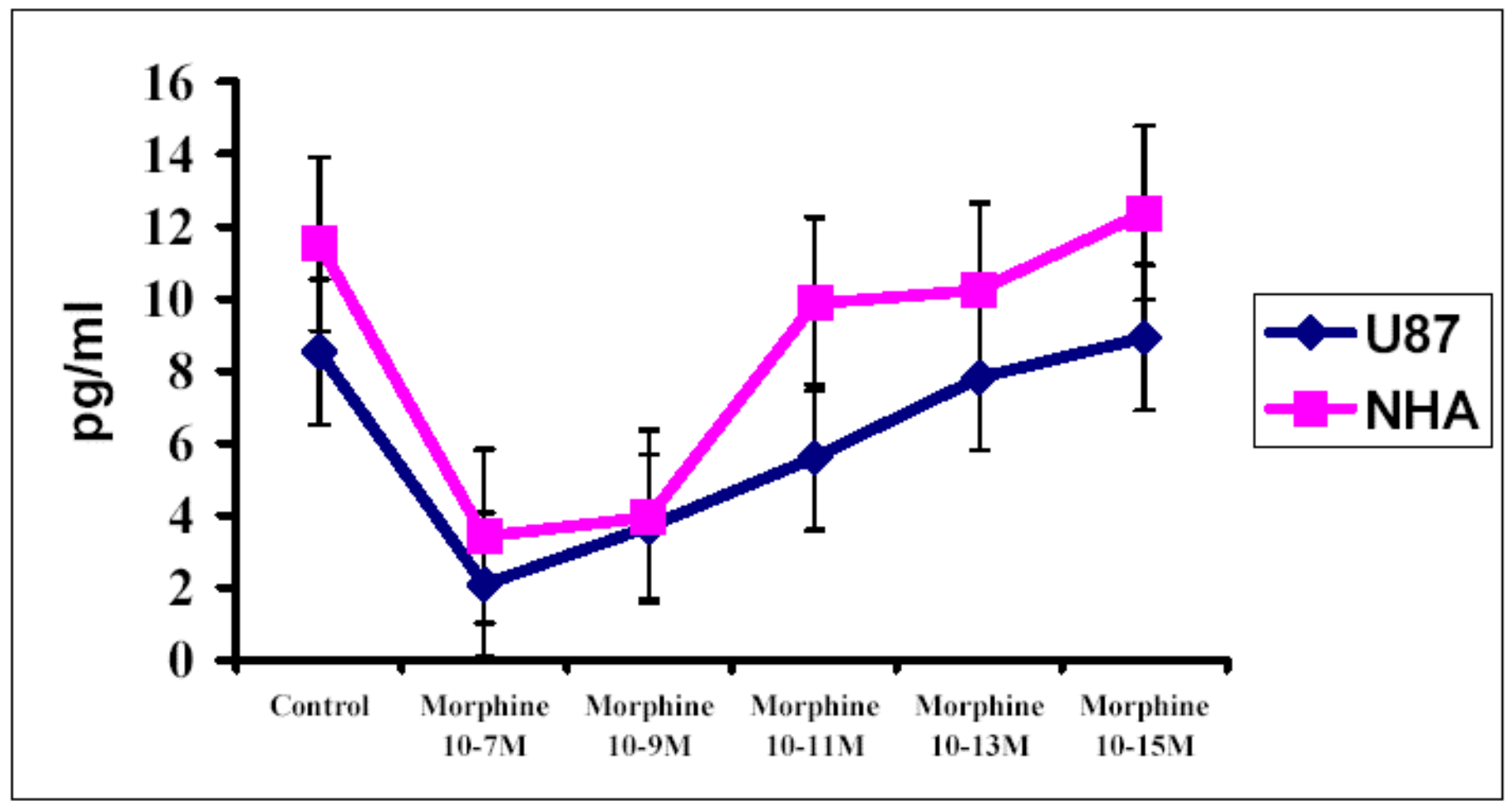

Fig. 2: Effect of morphine on IL-8 protein secretion in U87 and NHA cells. IL-8 protein levels as quantitated by ELISA assay kit from Biosource Inc. The minimum detectibility of the assay is $0.1 \mathrm{pg} / \mathrm{ml}$. Morphine at $10^{-7}$ and $10^{-9} \mathrm{M}$ suppressed IL-8 production.

\begin{tabular}{|c|c|}
\hline U373 & MIP-1ß (pg/ml) \\
\hline 1. Control & $1052.6 \pm 52.67$ \\
\hline 2. Morphine $10^{-7} \mathrm{M}$ & $675.9+21.43 p<0.0001$ \\
\hline 3. Morphine $10^{-9} \mathrm{M}$ & $727.6 \pm 27.59 \mathrm{p}<0.0001$ \\
\hline
\end{tabular}




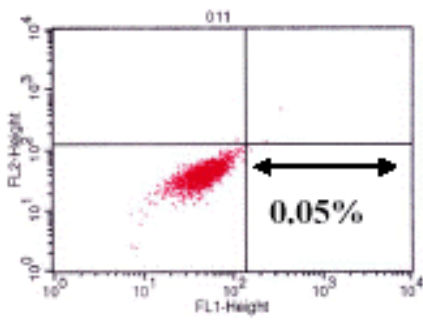

$3 \mathrm{~A}$

Isotype control

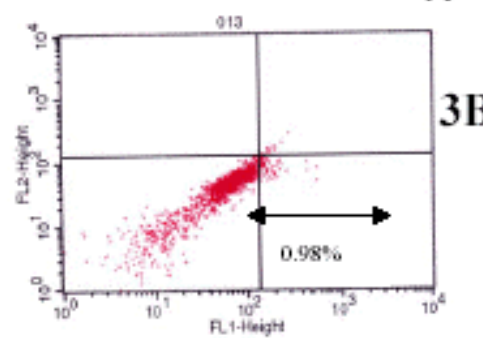

Untreated Control

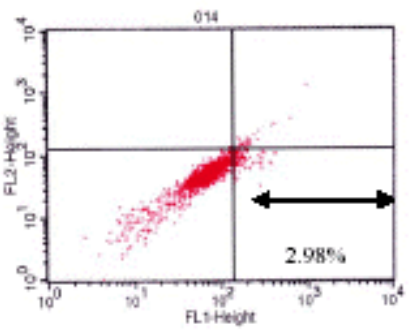

Morphine 10-7M

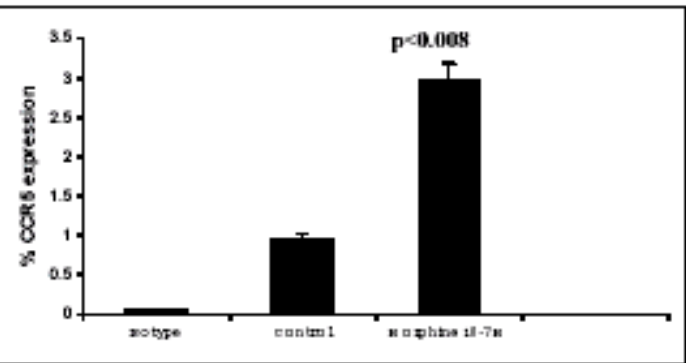

Fig. 3: Effect of morphine on the phenotypic expression of CCR5 on U373 cells. U373 cells were cultured with and without $10^{-7} \mathrm{M}$ morphine for 24 hr and subjected to FACS analysis. FL-1 (Fluorescence axis -1), represents the FITC labelled cells, while FL-2 (Fluorescence axis -2), represents the phycoerythrin or PE labelled cells. The CCR5 positive cells shown in the quandrants above are labelled with an anti CCR5 FITC- MAb. Panel 3A shows the Isotype Control used as a negative control to set quadrant markers. 3B: Untreated control cells showing that $0.95 \%$ of the total cells constitutively express CCR5 on their surface. $3 \mathrm{C}$ : Morphine treatment of U373 cells produces a significant increase in CCR5 positive cells to 2.98\%. 3D: Representative histogram showing Mean values \pm SD of CCR5 positive cells from 3 experiments. 


\section{MW}
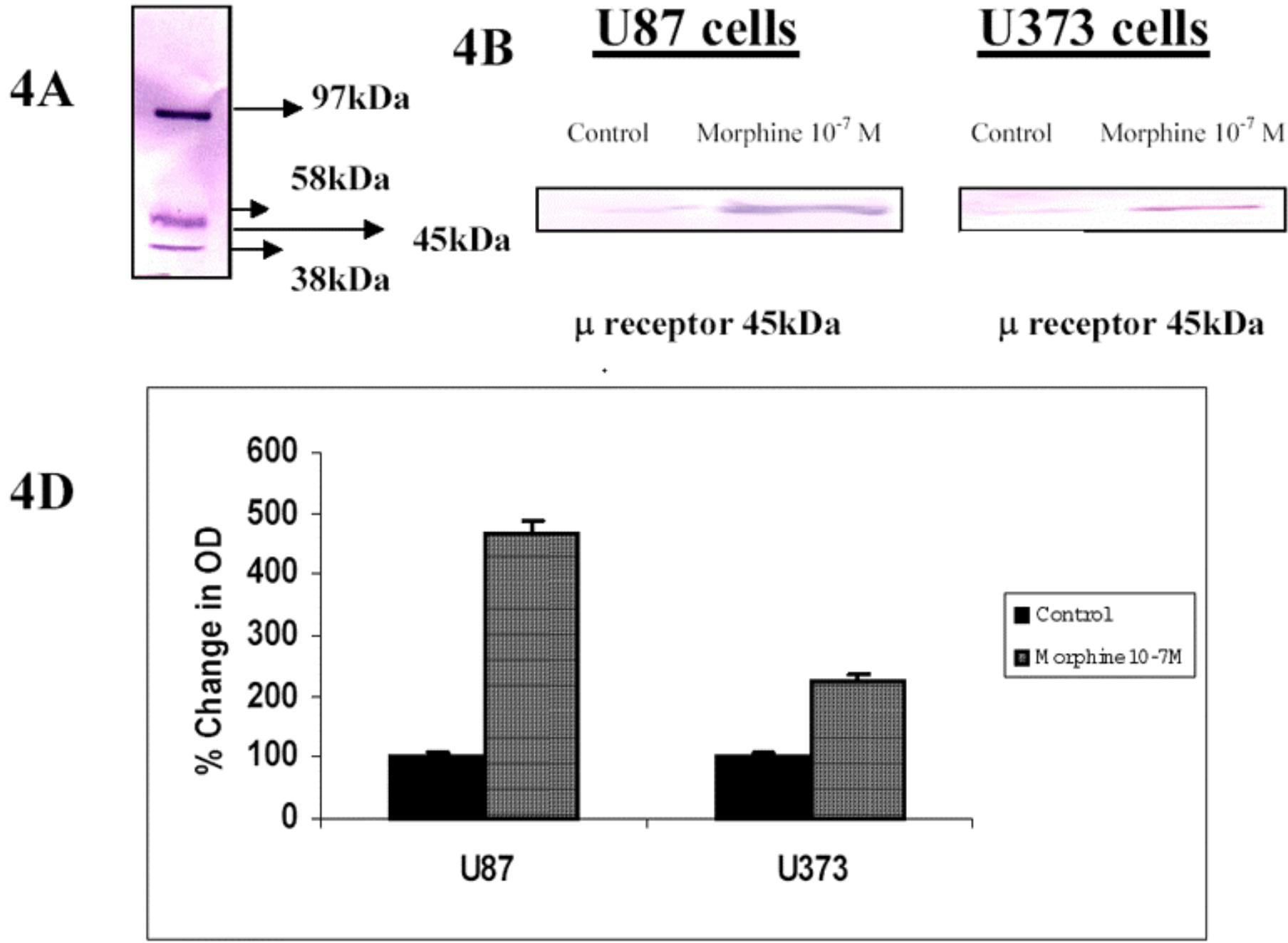

Fig. 4: Effect of morphine on the opioid $\mu$ receptor expression by U373, and U87. CNS cells were treated with $10^{-7} \mathrm{M}$ morphine for $72 \mathrm{hr}$. After incubation total protein was extracted and $30 \mu \mathrm{g}$ was separated on $7.5 \%$ SDS-Tris glycine PAGE. Gels were then subjected to western blot analysis using antibodies specific for the opioid $\mu$ receptor. The opioid $\mu$ receptor migrates as a $45 \mathrm{kDa}$ band. Fig. 4A: MW, Pre stained SDS-PAGE molecular marker standard. Fig. 4B \& 4C: untreated control and $10^{-7} \mathrm{M}$ Morphine treated cells in U87 and U373 cells. Fig. 4D: Reprepresentative histogram showing the percent increase in $\mu$ receptor expression between morphine treated and untreated controls in U87 and U373 cells. Treatment with morphine at $10^{-7} \mathrm{M}$ upregulated $\mu$ receptor expression in both U87 and U373 cells. 


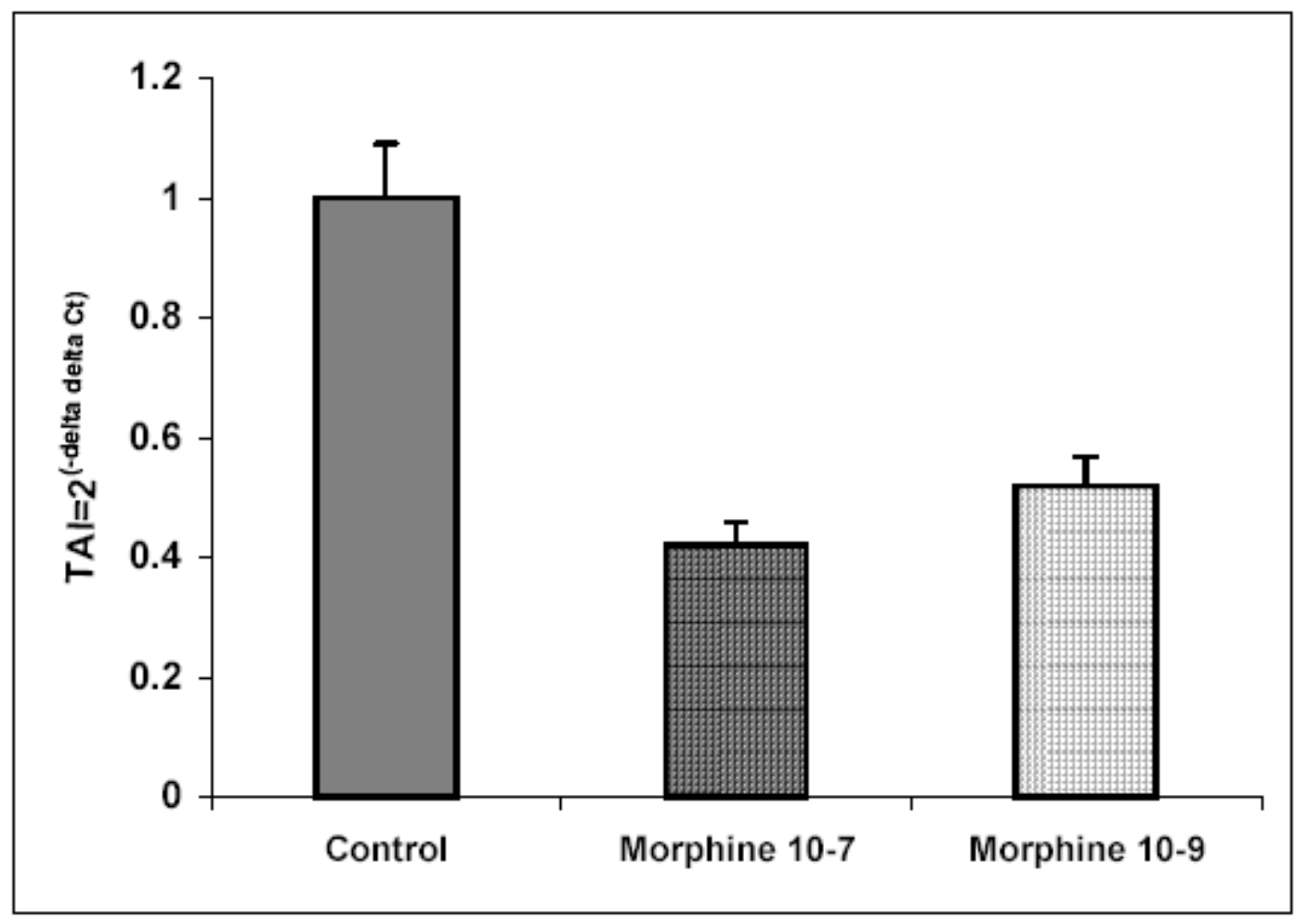

Fig. 5: MIP-1ß gene expression levels as quantitated by Real time quantitative $P C R$ using $S Y B R$ green master mix from $(\mathrm{Stratagene}, \mathrm{CA})$. $T A I=2^{-\Delta \Delta C t}$ gives the Transcript Accumalation Index or The Relative gene expression as compared to the control. Morphine at $10^{-7}$ and $10^{-9} \mathrm{M}$ downregulated MIP-1 $\beta$ gene expression.

\begin{tabular}{|c|c|}
\hline$\overline{\text { U373 }}$ & MIP-1及 $\left(\right.$ TAI $\left.=2^{-\Delta \Delta C t}\right)$ \\
\hline 1. Control & $1.0+0.00$ \\
\hline 2. Morphine $10^{-7} \mathrm{M}$ & $0.42 \pm 0.07 \quad \mathrm{p}<0.007$ \\
\hline 3. Morphine $10^{-9} \mathrm{M}$ & $0.52+0.03 p<0.002$ \\
\hline
\end{tabular}

